\title{
Diagnosis and Management of Alcoholic Liver Disease
}

\author{
Mohannad Dugum ${ }^{1}$ and Arthur McCullough*2 \\ ${ }^{1}$ Department of Internal Medicine, Medicine Institute, Cleveland Clinic, Cleveland, Ohio, USA; ${ }^{2}$ Department of Gastroenterology \\ and Hepatology, Digestive Disease Institute, Cleveland Clinic, Cleveland, Ohio, USA
}

\begin{abstract}
Alcohol is a leading cause of liver disease and is associated with significant morbidity and mortality. Several factors, including the amount and duration of alcohol consumption, affect the development and progression of alcoholic liver disease (ALD). ALD represents a spectrum of liver pathology ranging from fatty change to fibrosis to cirrhosis. Early diagnosis of ALD is important to encourage alcohol abstinence, minimize the progression of liver fibrosis, and manage cirrhosis-related complications including hepatocellular carcinoma. A number of questionnaires and laboratory tests are available to screen for alcohol intake. Liver biopsy remains the gold-standard diagnostic tool for ALD, but noninvasive accurate alternatives, including a number of biochemical tests as well as liver stiffness measurement, are increasingly being utilized in the evaluation of patients with suspected ALD. The management of ALD depends largely on complete abstinence from alcohol. Supportive care should focus on treating alcohol withdrawal and providing enteral nutrition while managing the complications of liver failure. Alcoholic hepatitis $(\mathrm{AH})$ is a devastating acute form of ALD that requires early recognition and specialized tertiary medical care. Assessment of $\mathrm{AH}$ severity using defined scoring systems is important to allocate resources and initiate appropriate therapy. Corticosteroids or pentoxifylline are commonly used in treating $\mathrm{AH}$ but provide a limited survival benefit. Liver transplantation represents the ultimate therapy for patients with alcoholic cirrhosis, with most transplant centers mandating a 6 month period of abstinence from alcohol before listing. Early liver transplantation is also emerging as a therapeutic measure in specifically selected patients with severe $\mathrm{AH}$. A number of novel targeted therapies for ALD are currently being evaluated in clinical trials.
\end{abstract}

Keywords: Alcoholism; Alcoholic cirrhosis; Alcoholic hepatitis; Liver transplantation.

Abbreviations: AASLD, American Association for the Study of Liver Diseases; $\mathrm{AH}$, alcoholic hepatitis; ALD, alcoholic liver disease; ALT, alanine aminotransferase; AST, aspartate aminotransferase; AUDIT, Alcohol Use Disorders Identification Test; AUROC, area under the receiver operating characteristic; CDT, carbohydrate deficient transferrin; EASL, European Association for the Study of the Liver; ELAD, extracorporeal liver assist device; GAHS, Glasgow Alcoholic Hepatitis Score; GGT, gamma glutamyl transferase; LSM, liver stiffness measurement; mDF, maddrey discriminant function; MELD, model for end-stage liver disease; NAFLD, nonalcoholic fatty liver disease; NASH, non-alcoholic steatohepatitis.

Received: 3 March 2015; Revised: 25 March 2015; Accepted: 30 March 2015

DOI: $10.14218 / \mathrm{JCTH} .2015 .00008$

*Correspondence to: Arthur McCullough, Department of Gastroenterology and Hepatology, Digestive Disease Institute, Cleveland Clinic, 9500 Euclid Avenue/ A30, Cleveland, Ohio 44195, USA. Tel: +1-216-444-2766, Fax: +1-216-4453889, E-mail: mcculla@ccf.org
(C) 2015 The Second Affiliated Hospital of Chongqing Medical University. Published by XIA \& HE Publishing Ltd. All rights reserved.

\section{Introduction}

Alcohol is consumed in most regions of the world and is a leading cause of liver disease. It is responsible for over 2.5 million deaths every year, and alcoholic liver disease (ALD) accounts for a large portion of alcohol-related morbidity and mortality. In 2010, alcoholic cirrhosis caused half a million deaths worldwide, accounting for $50 \%$ of all cirrhosis-related mortality. An additional 80,000 deaths resulted from alcoholrelated hepatocellular carcinoma. ${ }^{1}$

Patterns of alcohol consumption vary widely between different parts of the world and are affected by the local culture and habits. The duration of alcohol intake and amount of ingested alcohol are the most important predictors for the development of ALD. ${ }^{2}$ Other factors, such as coexistent liver diseases, obesity, metabolic syndrome, and cigarette smoking, also contribute to the overall risk of developing ALD. ${ }^{3}$ Women are more prone to develop ALD at lower amounts of alcohol consumption and are more likely to progress to liver fibrosis than men. ${ }^{4}$ This gender-specific susceptibility to alcohol hepatotoxicity has been attributed to women having: 1-lower gastric levels of alcohol dehydrogenase, leading to slower first-pass metabolism of alcohol; 2- higher gut permeability, causing higher endotoxin levels after alcohol ingestion that in turn lead to more aggressive oxidative stress and inflammation; 3- larger body fat content, resulting in a lower volume of distribution for alcohol. ${ }^{5}$ The incidence of binge drinking is increasing especially among young people; and although this is likely to influence the liver, its particular effects on liver disease are still not fully understood.

It is important to understand that ALD represents a spectrum of liver pathology that starts with fatty liver change, which is present in almost all heavy alcohol drinkers and is generally asymptomatic. Twenty percent to $40 \%$ of alcoholics develop fibrosis, $10-20 \%$ eventually progress to cirrhosis, and $1-2 \%$ of cirrhotics are diagnosed with hepatocellular carcinoma every year. ${ }^{6}$ While fatty liver is usually reversible upon cessation of alcohol use, other forms of ALD tend to progress despite abstinence. Alcoholic hepatitis is a particularly defined clinical entity characterized by rapid hepatic decompensation and in its severe form causes death in up to $50 \%$ of patients. ${ }^{4}$

Alcohol is a leading cause of cirrhosis and its subsequent complications, including portal hypertension, ascites, spontaneous bacterial peritonitis, variceal bleeding, hepatic encephalopathy, and hepatorenal syndrome. ${ }^{7}$ If they decompensate 
without receiving a liver transplant, one-third of patients with alcoholic cirrhosis who abstain from alcohol and two-thirds of those who continue to drink will die within 5 years. ${ }^{8}$ The overall incidence of hepatocellular carcinoma is increasing, and it is currently the main cause of death in patients with cirrhosis, including those with ALD. ${ }^{9}$ Fig. 1 summarizes the pathogenesis of ALD.

In this article, we review the diagnostic evaluation of patients with ALD with an emphasis on alcoholic hepatitis, discuss the current management options for these patients, and highlight new developing therapies.

\section{Diagnosis}

Early and accurate diagnosis of ALD is of paramount importance to provide these patients with the opportunity to reinforce the management of alcohol abuse, perform other lifestyle changes that can alter the progression of their liver disease, and provide specific screening protocols for cirrhosisrelated complications, including esophageal varices and hepatocellular carcinoma. Clinically, patients with ALD may exhibit the classical signs of liver disease, including parotid gland enlargement, gynecomastia, Dupuytren's contracture, dilated abdominal wall veins, and spider angiomas; but these are neither highly sensitive nor specific for ALD. A major challenge in the diagnosis of ALD is that patients with only fatty liver are usually asymptomatic and maintain an intact synthetic hepatic function. ${ }^{10}$

During the initial evaluation of suspected ALD, special attention to alcohol intake screening is warranted. A very recent report from the Centers for Disease Control and Prevention concluded that only one of six US adults, including binge drinkers, reported ever discussing alcohol consumption with a health professional. ${ }^{11}$ Many patients with ALD deny alcohol abuse or underreport their alcohol intake. ${ }^{10}$ Screening tests, such as the CAGE questionnaire and the Alcohol Use Disorders Identification Test (AUDIT), can be used to assess alcohol dependence or abuse. Since it is short, simple, and easy to administer, the CAGE test remains one of the most widely used screening tools (Table 1 ). Using a cutoff point of $\geq 2$, a meta-analysis showed a positive predictive value of 0.75 for detecting alcohol abuse. The sensitivity of the test varied considerably between the ambulatory and inpatient settings, where it performed much better in the latter, and the sensitivity dramatically decreased when a cutoff point of $>2$ was used. ${ }^{12}$ The CAGE test, however, does not focus on the amount of actual drinking, and therefore on its own has a limited value in the assessment of ALD. The AUDIT has proven to have good sensitivity and specificity in the clinical setting (Table 2). It has 10 questions exploring alcohol consumption, dependence, and alcohol related problems, and two cut-off points, one for dependence and one for risky drinking. ${ }^{13}$

It is important to distinguish patients with ALD from those with nonalcoholic fatty liver disease (NAFLD) who have evidence of hepatic steatosis without a cause for secondary hepatic fat accumulation and patients with nonalcoholic steatohepatitis (NASH) who have evidence of liver tissue inflammation with hepatocyte injury with or without fibrosis. By definition, NAFLD/NASH indicates the lack of evidence of ongoing or recent consumption of alcohol. Therefore, an initial step in evaluating patients with ALD is the documentation of heavy alcohol consumption. Several biochemical markers have been utilized for this purpose, including aspartate aminotransferase (AST), alanine aminotransferase (ALT), mean corpuscular volume, carbohydrate deficient transferrin (CDT), and gamma glutamyl transferase (GGT). ${ }^{14}$ GGT is highly sensitive and is the most widely used test to evaluate chronic alcoholism, but CDT is more specific for detecting daily ethanol ingestion. ${ }^{15}$ AST and ALT can be elevated with a typical AST:ALT ratio $>1.0$, although this is not highly specific for ALD. ${ }^{16}$

Evaluation for the presence and degree of liver fibrosis in patients with ALD is of paramount importance. Liver biopsy remains the gold standard diagnostic modality for detecting and staging liver fibrosis; however, it has its own limitations, including expense, sampling errors, and inter-observer variability, which could lead to understaging of cirrhosis. The percutaneous approach is especially painful and carries

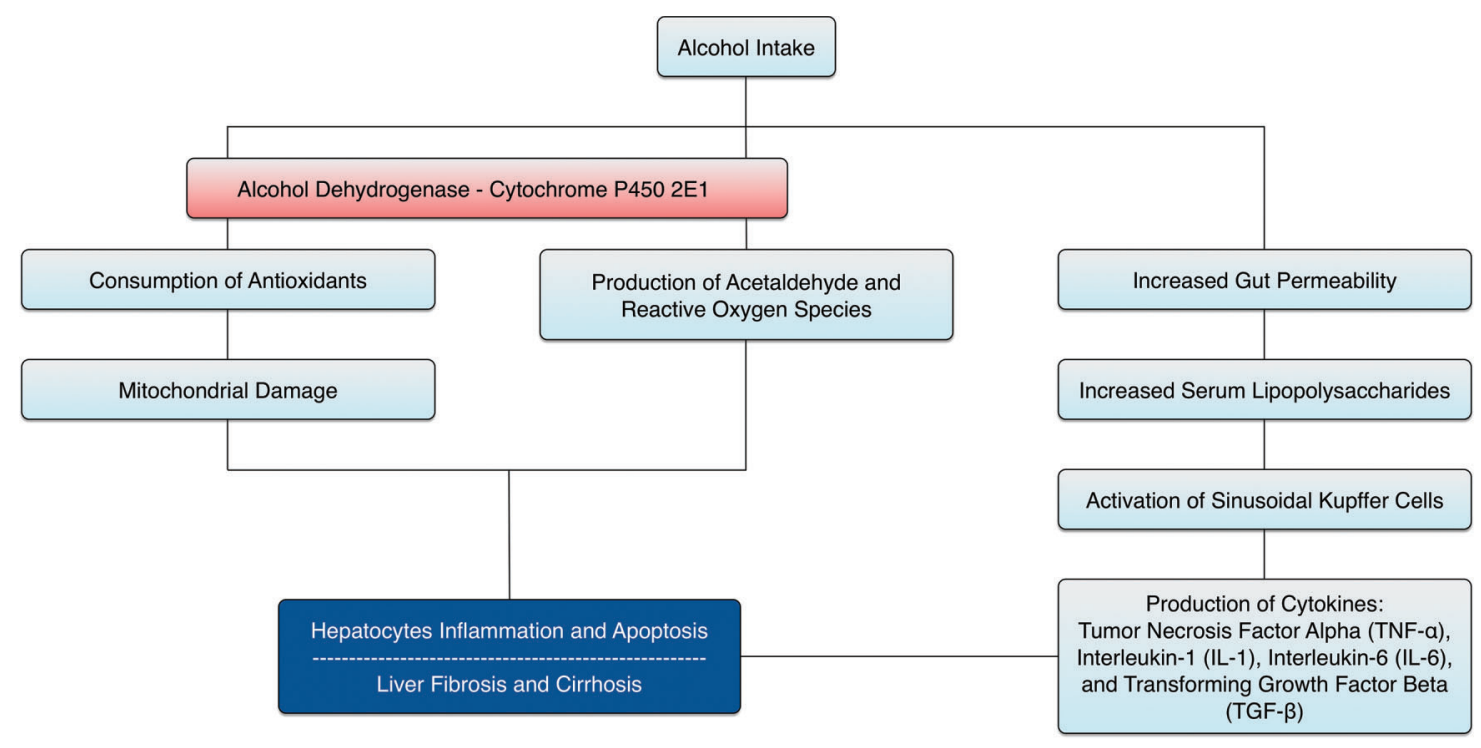

Fig. 1. Pathogenesis of alcoholic liver disease. 
Table 1. CAGE questionnaire ${ }^{12}$

Have you ever felt you should cut down on your drinking? Have people annoyed you by criticizing your drinking? Have you ever felt guilty about your drinking? Have you ever had a drink first thing in the morning to steady your nerves or to get rid of a hangover (eye opener)?

Item responses are scored 0 (No) or 1 (Yes), with a higher score an indication of alcohol problems. A total score of 2 or greater is considered clinically significant.

the risk of rare but serious complications, such as bleeding, infection, pneumothorax, hemothorax, and organ puncture. ${ }^{17}$ Subsequently, a number of noninvasive diagnostic modalities for detecting liver fibrosis, including certain biomarkers and imaging techniques, have been under development.

Among the biomarkers that have been validated for assessing fibrosis in patients with ALD are a number of patented biomarkers, such as FibroTest ${ }^{\circledR}$, Fibrometer $A^{\circledR}$, and Hepascore ${ }^{\circledR} .{ }^{18}$ FibroTest ${ }^{\circledR}$, which combines $\alpha 2$-macroglobulin, haptoglobin, GGT, ApoA1, and bilirubin, has demonstrated a good diagnostic potential for liver fibrosis in patients with ALD. ${ }^{19}$ FibrometerA ${ }^{\circledR}$ combines prothrombin time, a2-macroglobulin, hyaluronic acid along with age and has a similar diagnostic accuracy as FibroTest ${ }^{\circledR}, 20$ Hepascore ${ }^{\circledR}$ combines bilirubin, GGT, $\alpha 2$-macroglobulin, hyaluronic acid, age, and gender. These tests have similar diagnostic accuracies for fibrosis (area under the receiver operating characteristic curve (AUROCs $\sim 0.80$ ) and cirrhosis (AUROCs $\sim 0.90$ ) in patients with ALD, but combining them did not demonstrate an improved diagnostic yield. ${ }^{21}$

Several studies have evaluated the role of liver stiffness measurement (LSM) as a reliable noninvasive modality for assessing liver fibrosis in patients with ALD. The performance of FibroScan ${ }^{\circledR}$ (EchoSens, Paris, France) in particular has been widely validated in the assessment of liver fibrosis in patients with chronic hepatitis $\mathrm{C}$ virus infection, leading to further studies evaluating its utility in ALD. This system includes a probe with an ultrasonic transducer mounted on a vibrator. A low-frequency mild-amplitude vibration is transmitted from the vibrator to the liver tissue by the transducer. This vibration induces an elastic wave that propagates

Table 2. AUDIT questionnaire ${ }^{13}$

\begin{tabular}{|c|c|c|c|c|c|}
\hline \multirow[b]{2}{*}{ Question } & \multicolumn{5}{|c|}{ Score } \\
\hline & 0 & 1 & 2 & 3 & 4 \\
\hline $\begin{array}{l}\text { 1. How often do you have a drink } \\
\text { containing alcohol? }\end{array}$ & $\begin{array}{l}\text { Never (skip to } \\
\text { questions 9-10) }\end{array}$ & $\begin{array}{l}\text { Monthly } \\
\text { or less }\end{array}$ & $\begin{array}{l}2 \text { to } 4 \text { times } \\
\text { a month }\end{array}$ & $\begin{array}{c}2 \text { to } 3 \text { times } \\
\text { a week }\end{array}$ & $\begin{array}{l}4 \text { or more } \\
\text { times a week }\end{array}$ \\
\hline $\begin{array}{l}\text { 2. How many drinks containing alcohol } \\
\text { do you have on a typical day when } \\
\text { you are drinking? }\end{array}$ & 1 or 2 & 3 or 4 & 5 or 6 & 7,8, or 9 & 10 or more \\
\hline $\begin{array}{l}\text { 3. How often do you have five or more } \\
\text { drinks on one occasion? }\end{array}$ & Never & $\begin{array}{l}\text { Less than } \\
\text { monthly }\end{array}$ & Monthly & Weekly & $\begin{array}{l}\text { Daily or } \\
\text { almost daily }\end{array}$ \\
\hline $\begin{array}{l}\text { 4. How often during the last year have } \\
\text { you found that you were not able to } \\
\text { stop drinking once you had started? }\end{array}$ & Never & $\begin{array}{l}\text { Less than } \\
\text { monthly }\end{array}$ & Monthly & Weekly & $\begin{array}{l}\text { Daily or } \\
\text { almost daily }\end{array}$ \\
\hline $\begin{array}{l}\text { 5. How often during the last year have } \\
\text { you failed to do what was normally } \\
\text { expected from you because of } \\
\text { drinking? }\end{array}$ & Never & $\begin{array}{l}\text { Less than } \\
\text { monthly }\end{array}$ & Monthly & Weekly & $\begin{array}{c}\text { Daily or } \\
\text { almost daily }\end{array}$ \\
\hline $\begin{array}{l}\text { 6. How often during the last year have } \\
\text { you needed a first drink in the } \\
\text { morning to get yourself going after a } \\
\text { heavy drinking session? }\end{array}$ & Never & $\begin{array}{l}\text { Less than } \\
\text { monthly }\end{array}$ & Monthly & Weekly & $\begin{array}{l}\text { Daily or } \\
\text { almost daily }\end{array}$ \\
\hline $\begin{array}{l}\text { 7. How often during the last year have } \\
\text { you had a feeling of guilt or remorse } \\
\text { after drinking? }\end{array}$ & Never & $\begin{array}{l}\text { Less than } \\
\text { monthly }\end{array}$ & Monthly & Weekly & $\begin{array}{c}\text { Daily or } \\
\text { almost daily }\end{array}$ \\
\hline $\begin{array}{l}\text { 8. How often during the last year have } \\
\text { you been unable to remember what } \\
\text { happened the night before because } \\
\text { you had been drinking? }\end{array}$ & Never & $\begin{array}{l}\text { Less than } \\
\text { monthly }\end{array}$ & Monthly & Weekly & $\begin{array}{l}\text { Daily or } \\
\text { almost daily }\end{array}$ \\
\hline $\begin{array}{l}\text { 9. Have you or someone else been } \\
\text { injured as a result of your drinking? }\end{array}$ & No & & $\begin{array}{l}\text { Yes, but not } \\
\text { in the last year }\end{array}$ & & $\begin{array}{l}\text { Yes, during } \\
\text { the last year }\end{array}$ \\
\hline $\begin{array}{l}\text { 10. Has a relative or friend or a doctor or } \\
\text { another health worker been } \\
\text { concerned about your drinking or } \\
\text { suggested you cut down? }\end{array}$ & No & & $\begin{array}{l}\text { Yes, but not } \\
\text { in the last year }\end{array}$ & & $\begin{array}{l}\text { Yes, during } \\
\text { the last year }\end{array}$ \\
\hline
\end{tabular}

Sum the scores for each of the 10 questions. A total $\geq 8$ for men up to age 60 , or $\geq 4$ for women, adolescents, or men over age 60 is considered a positive screening test. 
through the tissue. Ultrasonic acquisitions are simultaneously performed to follow the propagation of the wave and measure its velocity. The wave velocity is directly related to tissue stiffness (the harder the tissue, the faster the wave propagation). ${ }^{22}$ FibroScan ${ }^{\circledR}$ has demonstrated reliability in predicting the degree of liver fibrosis. In a prospective study of patients with several chronic liver diseases, including ALD, LSM with FibroScan ${ }^{\circledR}$ had a positive predictive value of $91 \%$ and a negative predictive value of $92 \%$ for the diagnosis of cirrhosis, when a cutoff value of $17.6 \mathrm{kPa}$ was used. ${ }^{23}$ A study of ALD patients who underwent concomitant liver biopsy and LSM demonstrated excellent correlation between LSM and liver fibrosis: AUROC of 0.94 for the diagnosis of extensive fibrosis (cutoff value of $12.9 \mathrm{kPa}$ ) and AUROC of 0.87 for the diagnosis of cirrhosis (cutoff value of $22.6 \mathrm{kPa}$ ). ${ }^{24}$ Steatohepatitis often coexists with all stages of fibrosis in patients with ALD and can interfere with reliable assessment of fibrosis in these patients. Therefore, delaying LSM during alcohol withdrawal until AST is less than $100 \mathrm{U} / \mathrm{mL}$ may improve the diagnostic accuracy of the FibroScan ${ }^{\circledR}$. 25

\section{Management}

\section{General therapeutic measures in patients with ALD}

The cornerstone of ALD management at any stage is abstinence from alcohol. Improvement in fatty liver histology can occur as early as 2 weeks following discontinuation of alcohol use, while continuous alcohol consumption has been shown to increase portal pressure and worsen complication of portal hypertension, including variceal bleeding. ${ }^{26,27} \mathrm{~A}$ recent metaanalysis revealed that the overall survival of alcoholic cirrhotics significantly improves following at least 1.5 years of alcohol abstinence. ${ }^{28}$ In addition to improving health outcomes, alcohol abstinence is a prerequisite for liver transplantation, with most transplant centers requiring at least 6 months of documented abstinence before listing.

Protein-calorie malnutrition is a common finding in patients with ALD. Therefore, a careful evaluation of the nutritional status of these patients is important and proper nutrition should be emphasized. Addressing vitamins and trace minerals deficiencies (e.g. vitamin A, vitamin D, thiamine, folate, pyridoxine, and zinc) while maintaining a daily intake of $1.2-1.5 \mathrm{~g}$ of protein $/ \mathrm{kg}$ and $35-40 \mathrm{kcal} / \mathrm{kg}$ is recommended by the American Association for the Study of Liver Diseases (AASLD) in order to improve nitrogen balance. $^{29}$

Alcohol withdrawal syndrome is a serious condition that can complicate chronic alcoholism when patients suddenly decrease or discontinue their alcohol use. Within the first day after alcohol cessation, an increase in heart rate and blood pressure as well as irritability and hyperreflexia can occur. This can progress over the next few days to more severe complications, including seizures and delirium tremens. Benzodiazepines or clomethiazole are typically used to manage alcohol withdrawal, but other agents like gabapentin, clonidine, topiramate, and baclofen are also being utilized to avoid the potential side effects of benzodiazepines. ${ }^{30,31}$

\section{Alcoholism}

Brief motivational interventions should be routinely used in the management of alcohol use disorders, while individuals with heavy alcohol use benefit from early referral to alcohol rehabilitation programs that provide psychotherapy to promote initiation and maintenance of alcohol abstinence. Twelve step facilitation and cognitive-behavioral coping skills therapies have been utilized for this purpose with comparable outcomes. $^{32}$

Pharmacological agents can complement psychosocial treatments for alcoholism. Disulfiram, an inhibitor of acetaldehyde dehydrogenase that leads to an unpleasant reaction when alcohol is consumed, has been traditionally used in alcoholics. However, its use in ALD has been hindered by potential hepatotoxicity. Naltrexone (opioid receptor antagonist), acamprosate (glutamatergic receptor modulator), and topiramate (anticonvulsant) have also demonstrated efficacy in management of alcoholism, but they have not been evaluated in patients with end stage liver disease and are therefore not recommended in patients with ALD. Baclofen, a GABA receptor agonist, is a promising agent for increasing abstinence rates in alcoholic individuals and has demonstrated both efficacy and safety in patients with alcoholic cirrhosis. $^{33}$

\section{Alcoholic hepatitis}

Alcoholic hepatitis is a well-defined severe form of ALD that requires specialized medical care. An important concept in the management of alcoholic hepatitis is the assessment of disease severity. Several scoring systems have been developed for this purpose and demonstrate correlation with the clinical outcomes of those patients. These include the Maddrey discriminant function (mDF), the model for end-stage liver disease (MELD) score, the Glasgow Alcoholic Hepatitis Score (GAHS), and the ABIC (age, serum bilirubin, INR, and serum creatinine) score. The mDF was the first score developed and is the most widely used. An mDF of $\geq 32$ indicates severe alcoholic hepatitis and should trigger the initiation of corticosteroids. ${ }^{34}$ A MELD score of 21 has both high sensitivity and specificity for predicting mortality in patients with alcoholic hepatitis and is therefore an appropriate cutoff for initiating specific treatments. ${ }^{35}$ The GAHS and ABIC score are less commonly used due to lack of external validation. The Lille score includes six variables (age, albumin, bilirubin at day 0 , bilirubin day 7 , presence of renal insufficiency, and prothrombin time) and can be used to assess the response to corticosteroids after 1 week of treatment. Lille score values over 0.45 are associated with a significant 6 month mortality rate and are used to discontinue corticosteroids due to lack of response. ${ }^{36}$ Table 3 summarizes the calculations of the different scoring systems.

Infection screening is warranted in patients with alcoholic hepatitis, as a quarter of them are infected at the time of admission. While antibiotics are frequently used in this clinical setting, randomized clinical trials for empiric antibiotics use in these patients are lacking. ${ }^{37}$

The AASLD recommends starting corticosteroids in patients with severe alcoholic hepatitis, defined as mDF score of $\geq 32$, in the absence of contraindications such as sepsis, gastrointestinal bleeding, or hepatorenal syndrome. ${ }^{29}$ Although randomized clinical trials evaluating the role of corticosteroids in alcoholic hepatitis showed conflicting results in terms of survival benefit, a number of meta-analyses demonstrated reduced mortality in those with mDF of at least 32 or hepatic encephalopathy who were treated with corticosteroids. ${ }^{38}$ Typically, either oral prednisolone (active form of prednisone) $40 \mathrm{mg}$ daily or parenteral methylprednisolone $32 \mathrm{mg}$ 
Dugum M. et al: Alcoholic liver disease

Table 3. Prognostic scoring systems of alcoholic hepatitis

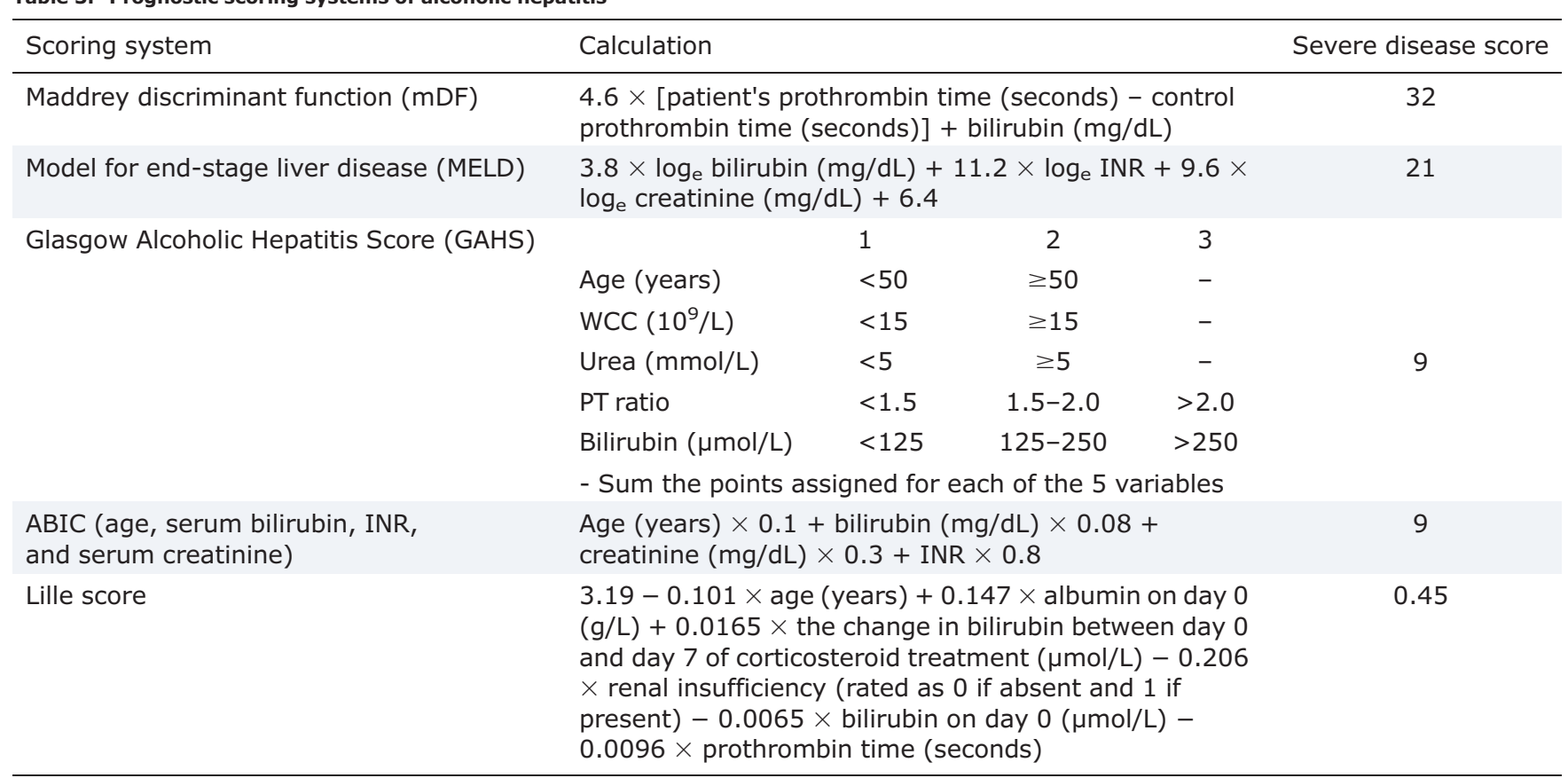

daily are administered for 4 weeks. The response to corticosteroids is assessed at 1 week of treatment using the Lille score. A Lille score $>0.45$ predicts a poor response $(75 \% 6$ month mortality) and should trigger the discontinuation of corticosteroids. Importantly, infections are more likely to occur if corticosteroids are continued beyond the first week in null-responders (i.e. Lille score $>0.56$ ). However, corticosteroid therapy should not be precluded in infected patients after initiation of appropriate antibiotic therapy. ${ }^{37}$

Pentoxifylline is an inhibitor of cytokines production, including TNF- $\alpha$, and can be used in patients with severe alcoholic hepatitis who have contraindications to corticosteroids. The survival benefit of pentoxifylline is mainly related to a reduction in the incidence of hepatorenal syndrome as the cause of death in these patients. ${ }^{39}$ However, pentoxifylline failed to demonstrate benefit in patients who have a poor initial response to corticosteroids. ${ }^{40}$ Other agents, such as infliximab, etanercept, $\mathrm{N}$-acetylcysteine, vitamin $\mathrm{E}$, silymarin, propylthiouracil, colchicine, and oxandrolone, have been studied as treatment options for alcoholic hepatitis but failed to demonstrate survival benefit. Fig. 2 summarizes a management approach for alcoholic hepatitis adapted from the guidelines of the AASLD and European association for the study of the liver (EASL).

\section{Alcoholic cirrhosis}

In addition to the general ALD therapeutic measures outlined earlier, patients with alcoholic cirrhosis require treatment for cirrhosis-specific complications while evaluating their candidacy for liver transplantation. Given the relatively high risk for hepatocellular carcinoma in those patients, screening is emphasized, as for any patient with liver cirrhosis. ${ }^{41}$ Patients with alcoholic cirrhosis should also be screened for alcohol-related cardiac, renal, pancreatic, and nervous system diseases. ${ }^{33}$

\section{Role of liver transplantation}

Given the shortage of donors and the risk of recidivism with consequent disease recurrence in the allograft, liver transplantation in patients with ALD has been an area of great medicosocial controversy. However, with the emergence of strong evidence of genetic and environmental influences on alcohol dependence, the view on alcoholism and ALD as being self-inflicted is slowly being reconciled. ${ }^{42}$

ALD is currently the second most common indication for liver transplantation in the US, surpassed only by chronic hepatitis $C$ virus infection. ${ }^{43}$ In most centers, the MELD score is used to prioritize those patients for liver transplantation. Alcoholics who receive liver transplants usually fair well, with similar graft and patient survival rates when compared to patients transplanted for nonalcohol related liver diseases. ${ }^{44}$ Most transplant centers mandate a 6 month period of abstinence from alcohol before listing for liver transplantation. This 6 month rule aims to allow patients with decompensated cirrhosis to recover from their liver disease and not require transplantation as well as to exclude the subset of patients who are at highest risk for recidivism, as demonstrated by psychological assessment. The estimates of recidivism posttransplant vary with reported rates up to $50 \%$ for any alcohol drinking and about $10 \%$ for heavy drinking. ${ }^{45}$ Patients with alcoholic cirrhosis who undergo liver transplantation have a higher incidence of certain malignancies as well as cardiovascular events following transplantation compared to cirrhotic patients with other underlying liver diseases. Therefore, screening for these conditions before and after liver transplantation is essential. ${ }^{33}$ 


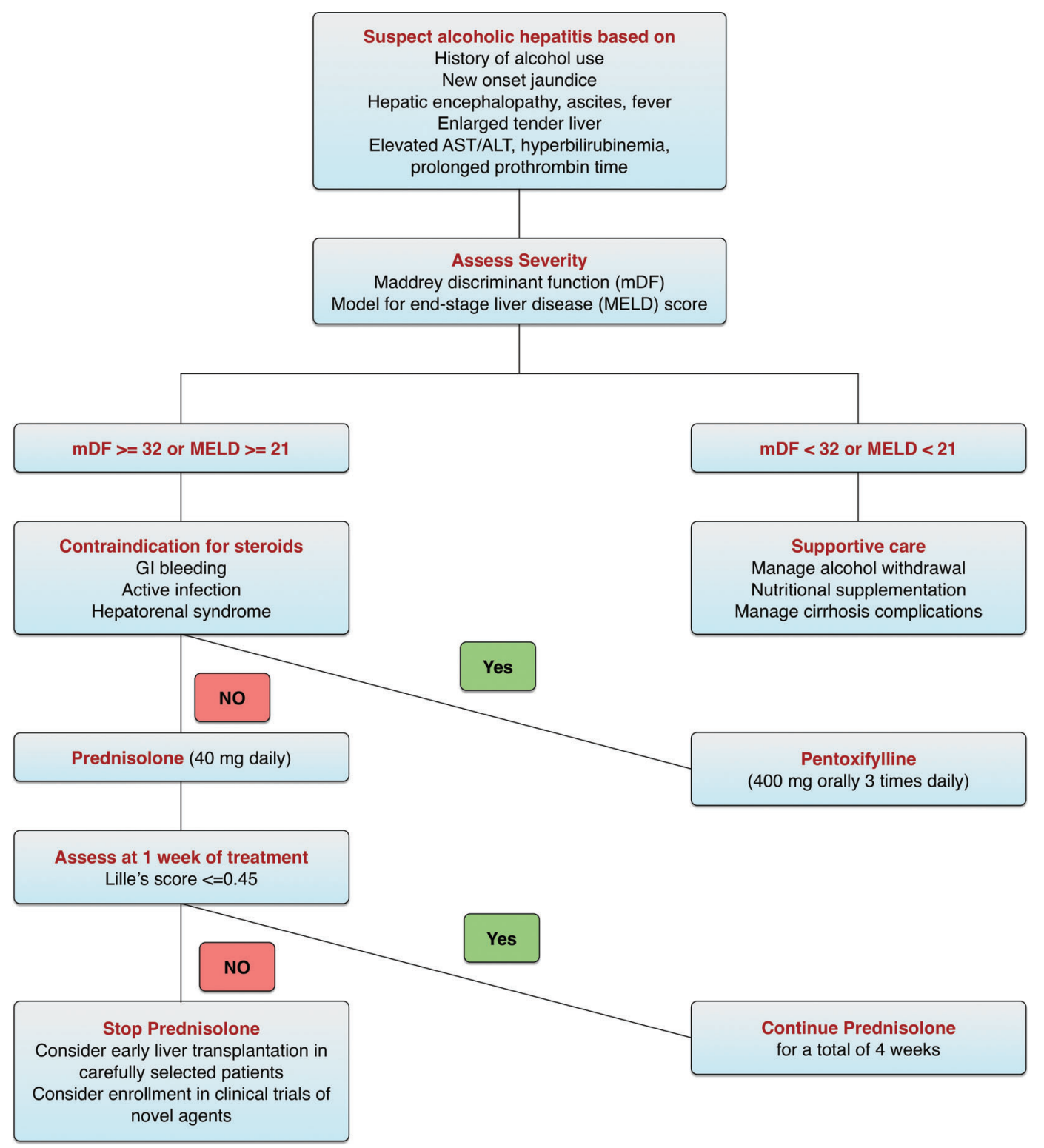

Fig. 2. Management of alcoholic hepatitis.

Patients with severe alcoholic hepatitis who fail medical therapy represent a particularly challenging group with regard to liver transplantation, as almost all are active drinkers at the time of presentation and many will have died by 6 months. ${ }^{46}$ Several recent studies support early liver transplantation in carefully selected patients with severe alcoholic hepatitis. One study utilizing the United Network for Organ Sharing database, demonstrated almost equal 5 year post-transplant graft and patient survival rates in patients with alcoholic hepatitis and alcoholic cirrhosis: $75 \%$ and $73 \%(p=0.97)$ and $80 \%$ and $78 \%(p=0.90)$, respectively. ${ }^{47}$ In another pivotal case-control prospective study, 26 patients with Lille scores $>0.45$ were listed for liver transplantation within a median of 13 days after nonresponse to medical therapy. The cumulative 6 month survival rate was higher among patients who received early LT than among those who did not ( $77 \%$ versus
$23 \%, p<0.001)$, and this survival benefit was maintained through 2 years of follow-up. ${ }^{48}$

\section{Therapeutic pipeline}

The progressive understanding of the underlying molecular basis of ALD has led to the development of a number of novel therapeutic targets for these patients. Specific molecular pathways related to ALD include oxidative stress, endotoxin and cytokine production, and certain immune regulators. A number of clinical trials evaluating these novel agents in patients with severe alcoholic hepatitis are already underway. Interleukin-22 (IL-22) is a promising therapeutic target for alcoholic hepatitis that has been associated with a reduction in hepatic steatosis following acute ethanol ingestion in animal models. IL-22 has also been shown to protect against 
hepatocyte injury and promote liver regeneration. However, IL-22 should be cautiously used in patients with alcoholic cirrhosis due to the concern for the development of hepatocellular carcinoma. ${ }^{49}$ Because caspases are involved in the induction of apoptosis, caspase inhibitors are thought to minimize alcohol-induced hepatocyte injury. An oral pancaspase inhibitor (Emricasan) is being evaluated in a clinical trial in patients with severe alcoholic hepatitis; and is proposed to inhibit TNF- $\beta$ induced-liver injury without blocking its beneficial effects on hepatocytes regeneration. Lipopolysaccharides derived from gram negative enteric bacteria promote Kupffer cells activation and subsequent production of several hepatoinjurious cytokines. Bovine colostrum enriched with IgG antilipopolysaccharide will be evaluated in combination with prednisolone in patients with severe alcoholic hepatitis. Anakinra (an IL-1 receptor antagonist with anti-inflammatory activity) in combination with pentoxifylline and zinc will be compared to methylprednisolone in a clinical trial recruiting patients with severe alcoholic hepatitis. The role of probiotics in moderately severe alcoholic hepatitis is also being explored. ${ }^{50}$ Another interesting clinical trial will evaluate the impact of extracorporeal liver assist device (ELAD) on the survival of patients with severe alcoholic hepatitis who have failed steroid therapy. ${ }^{51}$

\section{Conclusions}

ALD is a major health problem with rising incidence and prevalence. Early diagnosis is required to reinforce alcohol abstinence and improve patient survival. Clinical and laboratory diagnosis of ALD is enhanced by the emergence of a number of noninvasive diagnostics modalities, including biochemical panels and imaging techniques that measure liver stiffness. Subsequently, the diagnostic role of liver biopsy in ALD might diminish over time. Management of ALD relies on abstaining from alcohol while treating alcohol withdrawal, providing nutritional support, and managing cirrhosis-related complications. Liver transplantation is the best available option for patients with alcoholic cirrhosis as long as they abstain from alcohol. Alcoholic hepatitis is a severe form of ALD associated with high mortality. Patients with severe alcoholic hepatitis who fail medical therapy have very poor outcomes. New treatment agents for severe alcoholic hepatitis are under development, and the role of early liver transplantation in highly selected patients requires further research.

\section{Acknowledgements}

This work was supported in part by a grant from the National Institute on Alcohol Abuse and Alcoholism (U01AA021893) to Arthur McCullough.

\section{Conflict of interest}

None

\section{Author contributions}

Article design and manuscript writing (MD), article design, manuscript writing and critical revision (AM)

\section{References}

1. Rehm J, Samokhvalov AV, Shield KD. Global burden of alcoholic liver diseases. J Hepatol 2013;59:160-168. doi: 10.1016/j.jhep.2013.03.007.

2. Kamper-Jorgensen M, Gronbaek M, Tolstrup J, Becker U. Alcohol and cirrhosis: Dose-response or threshold effect? J Hepatol 2004;41:25-30. doi:10.1016/j. jhep.2004.03.002.

3. Gao B, Bataller R. Alcoholic liver disease: Pathogenesis and new therapeutic targets. Gastroenterology 2011;141:1572-1585. doi: 10.1053/j.gastro. 2011.09.002.

4. Poynard T, Mathurin P, Lai CL, Guyader D, Poupon R, Tainturier MH, et al. A comparison of fibrosis progression in chronic liver diseases. J Hepatol 2003; 38:257-265. doi: 10.1016/S0168-8278(02)00413-0.

5. Sato N, Lindros KO, Baraona E, Ikejima K, Mezey E, Jarvelainen HA, et al. Sex difference in alcohol-related organ injury. Alcohol Clin Exp Res 2001;25:40S45S. doi: 10.1111/j.1530-0277.2001.tb02371.x.

6. Teli MR, Day CP, Burt AD, Bennett MK, James OF. Determinants of progression to cirrhosis or fibrosis in pure alcoholic fatty liver. Lancet 1995;346:987-990.

7. Peery AF, Dellon ES, Lund J, Crockett SD, McGowan CE, Bulsiewicz WJ, et al. Burden of gastrointestinal disease in the United States: 2012 update. Gastroenterology 2012;143:1179-1187,e1-e3. doi: 10.1053/j.gastro.2012.08.002.

8. Chiang DJ, McCullough AJ. The impact of obesity and metabolic syndrome on alcoholic liver disease. Clin Liver Dis 2014;18:157-163. doi:10.1016/j.cld. 2013.09.006.

9. Bruix J, Gores GJ, Mazzaferro V. Hepatocellular carcinoma: Clinical frontiers and perspectives. Gut 2014;63:844-855. doi: 10.1136/gutjnl-2013-306627.

10. Grant BF. Barriers to alcoholism treatment: Reasons for not seeking treatment in a general population sample. J Stud Alcohol 1997;58:365-371. doi: 10. 15288/jsa.1997.58.365.

11. McKnight-Eily LR, Liu Y, Brewer RD, Kanny D, Lu H, Denny $\mathrm{CH}$, et al. Vital signs: Communication between health professionals and their patients about alcohol use-44 states and the District of Columbia, 2011. MMWR Morb Mortal Wkly Rep 2014;63:16-22.

12. Aertgeerts $B$, Buntinx $F$, Kester $A$. The value of the CAGE in screening for alcohol abuse and alcohol dependence in general clinical populations: A diagnostic meta-analysis. J Clin Epidemiol 2004;57:30-39. doi: 10.1016/S08954356(03)00254-3.

13. Saunders JB, Aasland OG, Babor TF, de la Fuente JR, Grant M. Development of the Alcohol Use Disorders Identification Test (AUDIT): WHO collaborative project on early detection of persons with harmful alcohol consumption-II. Addiction 1993;88:791-804. doi: 10.1111/j.1360-0443.1993.tb02093.x.

14. Hock B, Schwarz M, Domke I, Grunert VP, Wuertemberger M, Schiemann U, et al. Validity of carbohydrate-deficient transferrin (\%CDT), gammaglutamyltransferase (gamma-GT) and mean corpuscular erythrocyte volume (MCV) as biomarkers for chronic alcohol abuse: A study in patients with alcohol dependence and liver disorders of non-alcoholic and alcoholic origin. Addiction 2005;100:1477-1486. doi: 10.1111/j.1360-0443.2005.01216.x.

15. Bell H, Tallaksen CM, Try K, Haug E. Carbohydrate-deficient transferrin and other markers of high alcohol consumption: A study of 502 patients admitted consecutively to a medical department. Alcohol Clin Exp Res 1994;18:11031108. doi: 10.1111/j.1530-0277.1994.tb00088.x.

16. Nyblom H, Berggren U, Balldin J, Olsson R. High AST/ALT ratio may indicate advanced alcoholic liver disease rather than heavy drinking. Alcohol 2004;39: 336-339. doi:10.1093/alcalc/agh074.

17. Bravo AA, Sheth SG, Chopra S. Liver biopsy. N Engl J Med 2001;344:495-500. doi: 10.1056/NEJM200102153440706.

18. Mueller S, Seitz HK, Rausch V. Non-invasive diagnosis of alcoholic liver disease. World J Gastroenterol 2014;20:14626-14641. doi: 10.3748/wjg.v20. i40.14626.

19. Naveau S, Gaude G, Asnacios A, Agostini H, Abella A, Barri-Ova N, et al. Diagnostic and prognostic values of noninvasive biomarkers of fibrosis in patients with alcoholic liver disease. Hepatology 2009;49:97-105. doi: 10. 1002/hep.22576.

20. Naveau S, Raynard B, Ratziu V, Abella A, Imbert-Bismut F, Messous D, et al. Biomarkers for the prediction of liver fibrosis in patients with chronic alcoholic liver disease. Clin Gastroenterol Hepatol 2005;3:167-174. doi: 10. 1016/S1542-3565(04)00625-1.

21. Cales $\mathrm{P}$, Oberti F, Michalak S, Hubert-Fouchard I, Rousselet MC, Konate A, et al. A novel panel of blood markers to assess the degree of liver fibrosis. Hepatology 2005;42:1373-1381. doi: 10.1002/hep.20935.

22. Sandrin L, Tanter M, Gennisson JL, Catheline S, Fink M. Shear elasticity probe for soft tissues with 1-D transient elastography. IEEE Trans Ultrason Ferroelectr Freq Control 2002;49:436-446.

23. Foucher J, Chanteloup E, Vergniol J, Castera L, Le Bail B, Adhoute X, et al. Diagnosis of cirrhosis by transient elastography(FibroScan): A prospective study. Gut 2006;55:403-408. doi:10.1136/gut.2005.069153.

24. Nahon P, Kettaneh A, Tengher-Barna I, Ziol M, de Ledinghen V, Douvin C, et al. Assessment of liver fibrosis using transient elastography in patients with 
alcoholic liver disease. J Hepatol 2008;49:1062-1068. doi: 10.1016/j.jhep. 2008.08.011.

25. Mueller S, Millonig G, Sarovska L, Friedrich S, Reimann FM, Pritsch M, et al. Increased liver stiffness in alcoholic liver disease: Differentiating fibrosis from steatohepatitis. World J Gastroenterol 2010;16:966-972. doi:10.3748/wjg. v16.i8.966.

26. Diehl AM. Alcoholic liver disease: Natural history. Liver Transpl Surg 1997;3: 206-211.

27. Luca A, Garcia-Pagan JC, Bosch J, Feu F, Caballeria J, Groszmann RJ, et al. Effects of ethanol consumption on hepatic hemodynamics in patients with alcoholic cirrhosis. Gastroenterology 1997;112:1284-1289.

28. Xie YD, Feng B, Gao Y, Wei L. Effect of abstinence from alcohol on survival of patients with alcoholic cirrhosis: A systematic review and meta-analysis. Hepatol Res 2013. doi: 10.1111/hepr.12131.

29. O'Shea RS, Dasarathy S, McCullough AJ. Practice Guideline Committee of the American Association for the Study of Liver Diseases, Practice Parameters Committee of the American College of Gastroenterology. Alcoholic liver disease. Hepatology 2010;51:307-328. doi: 10.1002/hep.23258.

30. Mayo-Smith MF, Beecher LH, Fischer TL, Gorelick DA, Guillaume JL, Hill A, et al. Management of alcohol withdrawal delirium: an evidence-based practice guideline. Arch Intern Med 2004;164:1405-1412. doi:10.1001/archinte.164. 13.1405 .

31. Leggio L, Kenna GA, Swift RM. New developments for the pharmacological treatment of alcohol withdrawal syndrome. A focus on non-benzodiazepine GABAergic medications. Prog Neuropsychopharmacol Biol Psychiatry 2008; 32:1106-1117. doi:10.1016/j.pnpbp.2007.09.021.

32. Matching alcoholism treatments to client heterogeneity: Project MATCH posttreatment drinking outcomes. J Stud Alcohol 1997;58:7-29. doi: 10. 15288/jsa.1997.58.7.

33. European Association for the Study of Liver. EASL clinical practical guidelines: Management of alcoholic liver disease. J Hepatol. 2012;57:399-420. doi: 10. 1016/j.jhep.2012.04.004.

34. Maddrey WC, Boitnott JK, Bedine MS, Weber FL Jr, Mezey E, White RI Jr. Corticosteroid therapy of alcoholic hepatitis. Gastroenterology 1978;75:193199.

35. Dunn W, Jamil LH, Brown LS, Wiesner RH, Kim WR, Menon KV, et al. MELD accurately predicts mortality in patients with alcoholic hepatitis. Hepatology 2005;41:353-358. doi: 10.1002/hep.20503.

36. Louvet A, Naveau S, Abdelnour M, Ramond MJ, Diaz E, Fartoux L, et al. The lille model: A new tool for therapeutic strategy in patients with severe alcoholic hepatitis treated with steroids. Hepatology 2007;45:1348-1354. doi: 10. 1002/hep.21607.

37. Louvet A, Wartel F, Castel H, Dharancy S, Hollebecque A, Canva-Delcambre V, et al. Infection in patients with severe alcoholic hepatitis treated with steroids: Early response to therapy is the key factor. Gastroenterology 2009;137:541548. doi: 10.1053/j.gastro.2009.04.062.
38. Rambaldi A, Saconato $\mathrm{HH}$, Christensen $\mathrm{E}$, Thorlund $\mathrm{K}$, Wetterslev J, Gluud C. Systematic review: Glucocorticosteroids for alcoholic hepatitis-a cochrane hepato-biliary group systematic review with meta-analyses and trial sequential analyses of randomized clinical trials. Aliment Pharmacol Ther 2008;27: 1167-1178. doi: 10.1111/j.1365-2036.2008.03685.x.

39. Akriviadis E, Botla R, Briggs W, Han S, Reynolds T, Shakil O. Pentoxifylline improves short-term survival in severe acute alcoholic hepatitis: A doubleblind, placebo-controlled trial. Gastroenterology 2000;119:1637-1648.

40. Louvet A, Diaz E, Dharancy S, Coevoet H, Texier F, Thevenot T, et al. Early switch to pentoxifylline in patients with severe alcoholic hepatitis is inefficient in non-responders to corticosteroids. J Hepatol 2008;48:465-470. doi: 10. 1016/j.jhep.2007.10.010.

41. N'Kontchou G, Paries J, Htar MT, Ganne-Carrie N, Costentin L, Grando-Lemaire $\mathrm{V}$, et al. Risk factors for hepatocellular carcinoma in patients with alcoholic or viral C cirrhosis. Clin Gastroenterol Hepatol 2006;4:1062-1068. doi:10. 1016/j.cgh.2006.05.013.

42. Charlton MR, Burns JM, Pedersen RA, Watt KD, Heimbach JK, Dierkhising RA. Frequency and outcomes of liver transplantation for nonalcoholic steatohepatitis in the united states. Gastroenterology 2011;141:1249-1253. doi: 10. 1053/j.gastro.2011.06.061.

43. Burra P, Senzolo M, Adam R, Delvart V, Karam V, Germani G, et al. Liver transplantation for alcoholic liver disease in europe: A study from the ELTR (european liver transplant registry). Am J Transplant 2010;10:138-148. doi: 10. $1111 / j .1600-6143.2009 .02869$.

44. Murray KF, Carithers RL Jr. AASLD. AASLD practice guidelines: Evaluation of the patient for liver transplantation. Hepatology 2005;41:1407-1432. doi: 10.1002/hep.20704.

45. Tang H, Boulton R, Gunson B, Hubscher S, Neuberger J. Patterns of alcohol consumption after liver transplantation. Gut 1998;43:140-145. doi:10. 1136/gut.43.1.140.

46. Singal AK, Duchini A. Liver transplantation in acute alcoholic hepatitis: Current status and future development. World J Hepatol 2011;3:215-218. doi: 10. 4254/wjh.v3.i8.215.

47. Singal AK, Bashar H, Anand BS, Jampana SC, Singal V, Kuo YF. Outcomes after liver transplantation for alcoholic hepatitis are similar to alcoholic cirrhosis: Exploratory analysis from the UNOS database. Hepatology 2012;55:13981405. doi: $10.1002 /$ hep. 25544 .

48. Mathurin P, Moreno C, Samuel D, Dumortier J, Salleron J, Durand F, et al. Early liver transplantation for severe alcoholic hepatitis. N Engl J Med 2011;365: 1790-1800. doi: 10.1056/NEJMoa1105703.

49. Jiang R, Tan $Z$, Deng $L$, Chen $Y$, Xia $Y$, Gao Y, et al. Interleukin-22 promotes human hepatocellular carcinoma by activation of STAT3. Hepatology 2011; 54:900-909. doi: 10.1002/hep.24486.

50. Singal AK, Kamath PS, Gores GJ, Shah VH. Alcoholic hepatitis: Current challenges and future directions. Clin Gastroenterol Hepatol 2014;12:555-564. doi: $10.1016 /$ j.cgh.2013.06.013

51. https://www.clinicaltrials.gov. 